\title{
Small Fiber Neuropathy
}

National Cancer Institute

\section{Source}

National Cancer Institute. Small Fiber Neuropathy. NCI Thesaurus. Code C125389.

Neuropathy caused by damage to the small myelinated (A-delta) fibers or unmyelinated

$C$ fibers in the peripheral nerves. It manifests with burning pain, shooting pain, allodynia, and hyperesthesia. 